is the room and the need for improvement.I am, etc.,

$$
\text { Coton, Cambs. }
$$

apologize for venturing into your columns, but a legal view was asked for and I have read your medico-legal section for many years by reason of my father and wife both being subscribers.-I am, etc., John D. G. BenNetT.

SIR,-It is not surprising that the article by Mr. T. L. T. Lewis entitled "The Abortion Act" (25 January, p. 241) achieved a measure of publicity in the daily press. $\mathrm{He}$ is to be complimented for focusing attention on the early effects of the new Act by facts and figures devoid of emotional bias.

I wish, however, to correct the statement ascribed to me relating to the number of cases seen at St. Mary Abbots Hospital. During the five and a half months from 1 May to the middle of September 1968 226 patients requesting a termination of pregnancy were seen at two general hospitals in the Chelsea and Kensington group (and not one, as stated) by my two colleagues and me. Of these, 56 cases were subsequently admitted for termination of pregnancy, and 170 requests were refused. At this rate we would be expected to consider about 500 cases per annum.

The pressure on gynaecologists to interpret the Act in terms of "abortion-on-demand" is made clear by the high proportion of cases referred to us where no medical or social indication existed within the true meaning of the Act other than that of an unwanted pregnancy. These largely accounted for the number of refused requests. Each case is carefully considered, frequently involving the help and advice of the medical social worker, health visitor, psychiatrists, and occasionally, when indicated, the hospital and/or parish priest. As Mr. Lewis has stated, these cases are very time-consuming, demanding a judgement and wisdom which we cannot pretend to possess.-I am, etc.,

London W.1.

Frank DenNy.

\section{Marriage and the Law}

SIR,-As a family lawyer of some twenty years' experience both I and, I am sure, my profession can sympathize with the problem that $\mathrm{Mr}$. John J. Foley comes across among his unmarried obstetrical patients (25 January, p. 247). There are of course two weaknesses in his thesis that the mother and father should be permitted to marry, though below the legal minima laid down for marriage, so that any mental stress on the mother during pregnancy could be alleviated by the knowledge that her child would be born in wedlock.

Firstly, it initially reduces the age of marriage to the age at which the mother conceives, an age when she may not be in a position to know whether the proposed remedy is worse than the ill it purports to cure.

Secondly, it may be regarded as a means of defeating the legal minima against the wishes of parents and so forth. Medically there may be a good case for reducing the legal age for marriage nearer to the age of puberty ; that, however, is not for me to say.

I merely end by saying that the law may be an ass, but not such an ass as that, and

SIn,-The reduction of certification by doctors, and of excess sickness payments and undue absenteeism, could be effected partly by very simple means. Certificates for employers should answer two extra questions: Is the patient necessarily confined to his house? Is the patient fit to attend his place of work for general care ? Servicemen have always had their fitness for duty separated from their fitness to travel.

Minor illness and counterfeit minor illness are often indistinguishable and are fruitful causes of absenteeism, the major part of which is unnecessary. To take coryza, for example. The headmaster of a local private school wrote to each " new" parent. "If your son has a cold and is not particularly ill send him to school and we'll look after him." $\mathrm{He}$ found it worked admirably and there was no increase in morbidity. My partner and I have the usual average number of colds, say five each per annum, yet our total number of days off for that complaint in the past 20 years is nil, though we have occasionally switched night duties. Some patients have at least a week off for it and some take two or three.

If the major firms and especially Government departments who tolerate sickness on full pay were to set up sick quarters to receive and care for certificated personnel who were not confined to their houses they would need far less space than their present sickness rates would suggest. Minor illness is a minor holiday for a number of people. Holidays at work, with comfortable chairs and improving books in sick quarters, would come round less often and go away more quickly. Patients attending hospital departments, those transparently incapable of work for long periods, and those with good work records would be excused by factory doctor, nurse, or manager from attending every working day.

There are things the Government could do to help. If it cut out the repayment of

SIR,-We were interested to see the articles on outpatient operations and the resulting saving of time, money, and facilities (18 January, pp. 174 and 176).

For the last three years, in the Windsor Hospital Group, minor orthopaedic operations have been carried out on outpatients, using regional intravenous anaesthesia. The facilities for these operations have been provided by the Slough Industrial Health Service. The advantages mentioned by $\mathrm{Mr}$. J. Alexander Williams and Drs. D. Dean and B. R. Wilkinson are fully recognized. In addition, these arrangements avoid the problems created when patients leave children, provision for whom often requires the husband or wife being away from work when inpatient operations take place.

Since starting the scheme 186 operations "waiting days" it would not tempt people to stay off long enough to collect it. Insurance stamps are all or nothing, and small firms are unwilling to pay full stamps for fractions of a week. The introduction of a no-claims (or nearly no-claims) bonus for good health would be paradoxical but very effective. I have always thought it improved my driving. Two years or more of no claims might allow of two weeks' self-certification in the following year. Above all, let experiments like these be made in selected areas, and find out what really is necessary and what is merely historical.-I am, etc.,

Bradford, Yorks.

Н. В. Minchoм.

SIR,- - I read the articles on certification for sickness (18 January, pp. 144 and 147) with great interest, but an important facet of this subject which has escaped public discussion is the growing use of the official N.H.S sick note by private firms, a large proportion of which will now accept nothing else.

These certificates are clearly printed in red capitals "For National Insurance Purposes Only," and the Ministry official to whom I spoke agreed that no firm had any right to them, but said that the use of the official Ministry certificates by private organizations received tacit Ministry approval, largely because it had been going on for so long The certificates carry a diagnosis. This diagnosis is seen by the nurse, members of personnel departments, trade union officials, clerks, and presumably anyone who is really interested. The certificates are incorporated into a firm's own private sick-pay and pensions scheme and certainly play an important part in the administrative machinery of these organizations.

With concerns such as the G.P.O. the argument is that they are a Government concern, and thus entitled to the "official" form. In this respect they are manifestly no different from other concerns with a purely private basis. It would be interesting to find out what other doctors' views are about this misuse of the N.H.S. certificate and if any measures can be taken to right matters.-I am, etc.,

Stevenage, Herts.

R. E. Dawson.

\section{Outpatient Operations}

have been completed for the following conditions:

$$
\begin{array}{llll}
\text { Carpal tunnel syndrome } & \ldots & 69 . \\
\begin{array}{l}
\text { Ganglia } \\
\text { de Quervain's syndrome }
\end{array} & \ldots & 75 \\
\text { "Trigger" finger } & \ldots & \ldots & 20 \\
& & & \frac{22}{186}
\end{array}
$$

Patients are seen the day after operation at the clinic, and again 10-14 days later for suture removal. A follow-up outpatient appointment is made for one month after this. Where necessary rehabilitation for return to work is arranged through the Industrial Health Service. At the time of operation a letter is sent to the general practitioner for information, but he is usually not troubled during the postoperative period. N.H.S. certificates are issued at the clinic on the day 
of operation. Our experience would suggest that increasing use should be made of outpatient operations.-We are, etc.,

\section{G. P. ARDEN}

Slough Industrial Health Service,
Slough, Bucks.

SIR,-The articles on outpatient surgery by Mr. J. A. Williams (18 January, p. 174) and by Drs. D. Dean and B. R. Wilkinson (p. 176) prompt me to relate a piece of medical history which also is concerned with outpatient surgery.

In a paper he read in the section of diseases of children at the 77th meeting of the British Medical Association in 1909, which was held in Belfast, J. H. Nicoll, ${ }^{1}$ of Glasgow, presented an account of 7,392 operation he had done in the outpatient department of the Royal Glasgow Hospital for Sick Children in the period 1899-1908. These in cluded 610 for talipes, 406 for hare-lip and cleft palate, 36 for spina bifida, 165 for mastoid disease, and, in the period 1903-8, 220 for hernia. He had also done many operations for tuberculous glands, bones, and joints. All the children were treated as outpatients. The results were as good as those in children treated as inpatients. In the ensuing discussion Stiles, ${ }^{1}$ of Edinburgh, was opposed to operating for hernia in the outpatient department, but Robert Campbell, ${ }^{1}$ of Belfast, agreed with Nicoll and said it was his own practice in the Belfast Hospital for Sick Children. Andrew Fullerton ${ }^{1}$ gave warning about possible medico-legal complications, but added that with the authority of three such well-known surgeons as the previous three speakers he was sure more work would be done in the outpatient theatre, and the benefits of children's hospitals would be much extended thereby.

How the practice was extended in the Belfast Hospital for Sick Children is shown in letter Fullerton ${ }^{2}$ wrote to the B.M.F. in 1913: "So convinced was I by Mr. Nicoll's results" that I immediately began to add hernia and hydrocele to the list of my outpatien operations, and my colleagues followed the same course. Since then we have enormously extended our scope, and personatly I have no hesitation in operating on hare-lip, sometimes cases of cleft palate, knock-knee and bow leg in children about 4-5 years of age, enlarged tonsils, adenoids, naevi, tuberculous joints in the upper extremity, glands, tumours, and cysts in the neck and many other conditions requiring surgical intervention. A few weeks ago I removed in the outpatient theatre an occipital meningocele with an entirely successful result. In this way numbers of children are relieved who could not otherwise have been properly treated on account of shortness [sic] of beds. The results have borne very favourable comparison with those obtained in the wards, and the utility of the hospital has been very greatly increased...."

All this work was of course done in children's hospitals, but the principle is that of the practice now being advocated in 1969 and described by one of the writers-in the matter of repair of hernia at least-as " revolutionary." Nicoll and Campbell and Fullerton and their colleagues were working in the days when anaesthetic technique was crude and the means of controlling infection almost non-existent. Moreover, the domiciliary nursing service available to them for the aftercare of their patients was as yet poorly developed.-I am, etc.

\section{H. G. Calwell.}

Whitehead, Co. Antrim

\section{REFERENCES}

Nicoll, J. H., Proceedings of 77th Annual Meeting of the British Medical Association, Brit. Fullerton, A., Brit med.

Nicoll, J. H., Brit. med. '尹., 1913, 1, 470. 1913, 1, 384

SIR,-Y Your Middle Articles on 18 January were of great interest. The conclusions from the five attitude studies (p. 172) and the recommendations of the special subcommittee of the General Practitioners' Liaison Committee of the Birmingham Regional Hospital Board will be welcomed by many doctors in general practice.

The articles "The Surgeon's View" (p. 174) and "As the General Practitioner Sees It" (p. 176), however, are most disturbing. Outpatient operations are shown to be a valuable way of saving hospital beds for more serious cases and a means of avoiding the long delays in admission for minor surgical procedures, but the general practitioner's role in this is humiliating. He is doing work which, in hospital, would be delegated to the most junior house-surgeon, and in many cases to the nursing staff. How this can be described as satisfying is difficult to understand. It is not likely to encourage the young graduate to regard general practice as a worth-while career. It seems that the general practitioner is regarded by his surgical colleague as unqualified to take any part in the hospital treatment of surgical cases. Why should surgery differ from general medicine, paediatrics, and psychiatry? Many surgical procedures are well within the capabilities of general practitioners given the opportunity for training under supervision. Until the National Health Service was introduced, and the pressures of large lists and consequen lack of time made it impossible, many doctors were doing such minor surgery.

If we are to work in collaboration with our specialist colleagues in the future, it is to be hoped that we shall have the opportunity to train ourselves for more interesting and active participation than is exemplified in these articles.-We are, etc.,

\section{H. M. Titcombe.} P. H. Dootson.

\section{Cheadle Hulme, Cheshire.}

\section{Puerperal Thromboembolism}

SIR,-We are grateful to the several correspondents who have commented on our articl on the relation of puerperal thromboembolism to the inhibition of lactation (5 October p. 19) and on allied matters. It was of special interest to have the report of $\mathrm{Mr}$. D. G. Millar and Dr. E. G. Robertson on the experience at Newcastle (16 November p. 452) and to have their confirmation of our findings. It would appear that in each of the three centres-Cardiff, Liverpool, and Newcastle-the overall figures indicate that puerperal thromboembolism occurs more frequently in women who have lactation inhibited with oestrogens than in those who breast-feed. The only point on which there is any difference of opinion is the relative importance of the several predisposing factors concerned-namely, age, parity, mode of delivery, and oestrogens.

One of the difficulties emphasized in our paper and by some of your correspondents is that the number of cases available for analysis in any centre is too small to reach final conclusions. This may explain why $\mathrm{Dr}$. Mavis Gunther and Dr. E. I. Kohorn did not find firm evidence that the administration of oestrogens plays any part in the incidence of thromboembolism among women delivered at University College Hospital (21 December, p. 769). Their statistics also included the far commoner condition of superficial phlebothrombosis, which was excluded from the surveys undertaken in Cardiff, Newcastle, and Liverpool. Puerperal superficial phlebothrombosis is a condition which differs from deep venous thrombosis in the time of its occurrence and probably in its aetiology. It appears to be determined almost entirely by blood stasis, especially that occurring during labour, so it usually manifests itself within 48 hours of delivery, before lactation habit is likely to have any effect. There are other differences too, and it would therefore seem wise not to include superficial phlebothrombosis in any study of the kind under consideration; it serves to confuse still further an already complicated picture.

Dr. D. G. Daniel and his colleagues in Cardiff, who must be given all the credit for first recognizing a possible relationship between puerperal thromboembolism and inhibition of lactation with oestrogens, are concerned (16 November, p. 451) that we misrepresented or misquoted some of their original observations. If so, it was quite unintentional, and we regret it. As we emphasized in our paper, it is extremely difficult to know how best to handle the sort of statistical material which we collected, and it can be presented in several ways. For this reason we were careful to publish as many relevant figures as possible, the object being to permit those interested in the problem to apply their own method of analysis. We are therefore glad to have the interpretation applied by Dr. Daniel and his colleagues. Their handling of our statistics does not alter the over-all conclusions, but brings them a little closer to their own

Despite this, we are left with an overriding doubt about the significance of all reported findings, because the growing tendency to suppress lactation in recent years has not been accompanied by an increase in the number of cases of puerperal thromboembolism; this is true for both national and individual hospital statistics. There also remains unexplained the fact that a large proportior of episodes of thromboembolism now occur during pregnancy rather than after delivery. Both these matters were emphasized in our paper, but our evidence was limited. It is therefore very valuable to have the observations of $\mathrm{Mr}$. Millar and $\mathrm{Dr}$. Robertson on these aspects of the problem.

Setting aside these doubts, it still seems to us that, according to the evidence available at present, the administration of oestrogens to inhibit lactation is only one factor which can determine the occurrence of puerperal thromboembolism, and that it is not the most important. It only operates when other and 